\title{
Destinasyon Deneyimi ve Sadakati Arasındaki İlişkide Destinasyon Aidiyetinin Aracı Rolü*
}

\section{The Mediating Role of Destination Attachment on the Relation between the Destination Experience and Destination Loyalty}

\author{
Yrd. Doç. Dr. İlker TÜRKERI \\ Lefke Avrupa Üniversitesi \\ Turizm ve Otel İşletmeciliği Yüksekokulu \\ Lefke, Kuzey Kıbrıs Türk Cumhuriyeti \\ E-posta: iturkeri@eul.edu.tr
}

Öz

$\mathrm{Bu}$ çalışmanın amacı satın alma davranışlarındaki tutarlılığı ifade etmek için kullanılan sadakat kavramı ile turistlerin ziyaret ettikleri destinasyonda edindikleri deneyim arasındaki ilişkiyi aidiyet kapsamında ortaya koymaktır. Bu amaçla, destinasyonları tekrar ziyaret eden ve aynı zamanda ziyaret ettikleri destinasyonları başkalarına tavsiye ederek destinasyonların pazarlanmasını kolaylaştıran turistlerin destinasyon sadakati oluşum sürecine doğrudan ve dolaylı etki eden değişkenler bir model kapsamında incelenmiştir. Kurulan yapısal eşitlik modelinde destinasyon deneyiminin ve destinasyon aidiyetinin destinasyon sadakati üzerindeki etkileri yol analizi çizilerek test edilmiştir. Analiz için kullanılan veriler Fethiye'yi ziyaret eden 395 turistten anket tekniği kullanılarak elde edilmiştir. Araştırma sonuçları, destinasyon deneyiminin sadakat üzerinde etkili olduğunu ve bu ilişkiye destinasyon aidiyetinin aracılık ettiğini göstermektedir.

Anahtar Kelimeler: Deneyim, Aidiyet, Sadakat, Destinasyon, Fethiye.

\section{Abstract}

The aim of this study is to address the concept of loyalty used to express coherence in purchasing behaviors on a touristic destination. For this purpose, a model that directly and indirectly influences in the formation process of destination loyalty of tourists, which makes it easier to market destinations by revisiting destinations and also recommending them to others, has been examined within a model. In the constructedstructural equation model, the affects of destination experience attachment on destination loyalty have been tested by drawing path analysis. In order to be able to perform the analysis, the data of the research have beencollected by using the questionnaire technique from 395 tourists who visit Fethiye. The results of the research show that destination attachment have mediating effect on the relation between the destinastion experience and destination loyalty.

Key Words: Experience, Attachment, Loyalty, Destinastion, Fethiye.

\footnotetext{
* Bu çalışma, Destinasyon Deneyimi, Bilinirliği ve Aidiyeti Kapsamında Destinasyon Sadakatine Yönelik Bir Model Önerisi: Fethiye Örneği” adlı Doktora Tezi'nden türetilmiştir.
} 


\section{Giriş}

Farklı ürün ve hizmetlerin bir araya getirilmesi ile oluşan turizm ürünleri diğer ürünler gibi hedef kitleye ulaştırılmak için fiyat, tutundurma ve dağıtım stratejileri ile pazarlama faaliyetlerini en etkili şekilde yürütmektedir. Ancak diğer ürünlerden farklı olarak dağıtım kanalı tersine işlemekte yani ürün müşteriye değil müşteri ürüne gitmek durumundadır. Diğer bir deyişle turistik birer ürün olan destinasyonların dağıtım kanalının oluşturulması turistin destinasyona ziyareti ile mümkün olabilmektedir. Her ne kadar destinasyon ziyaret sayısı destinasyonun başarısı ve rekabet edebilirliği açısından önemli olsa da destinasyona tekrar ziyaretlerin gerçekleştirilmesi daha önemli bir konudur. Destinasyonu tekrar ziyaretler ise sadık ziyaretçiler oluşturmaktan geçmektedir.

Destinasyon sadakatinin tekrar ziyaret ve başkalarına tavsiye etme davranışlarını içermesinden dolayı bu kavram hem tekrarlanan ziyaretler ile destinasyona rekabet avantajı kazandırmakta hem de mevcut müşteriyi elde tutarak yeni müşteri arayışının önüne geçmektedir. Bununla birlikte destinasyon sadakatinin, olumlu ağızdan ağza pazarlama ile reklam, tanıtım ve yeni ziyaretçi elde etmede maliyeti düşürücü etkileri bulunmaktadır.

Destinasyon sadakati değişkenin oluşturulabilmesi için öncül değişkenlerin bulunması destinasyona bahsedilen avantajları sağlaması açısından önemlidir. Daha önce yapılan araştırmalar(hizmet kalitesi (Yılmaz, 2011; Yılmaz ve Ön Esen, 2015),memnuniyet (Kozak vd.,2004; Yoon ve Uysal,2005; Valle vd.,2006; Chi ve Qu, 2008; Mendes vd.,2010; Yılmaz, 2011; Deng ve Pierskalla, 2011; Chi,2011; Myagmarsueren ve Chen, 2011; Chi, 2012; Forgas-Coll vd., 2012; San Martin vd.,2013; Sun vd.,2013; Sırakaya- Türk vd., 2015; Wu, 2016), tatil deneyimi (Chen ve Gürsoy,2001; Mendes vd.,2010; Chi, 2012; Kim ve Brown, 2012; San Martin vd.,2013; Sırakaya- Türk vd., 2015), destinasyon imajı (Hernandez vd., 2006; Chi ve Qu, 2008; Yılmaz, 2011; Bianchi ve Pike,2011; Chi,2011; Sun vd.,2013; Frangos vd., 2015; Wu, 2016), aidiyet (Mechinda vd.,2009), bilinirlik (Mechinda vd., 2009; Sun vd.,2013), algılanan değer (Mechinda vd., 2009; Deng ve Pierskalla, 2011; Forgas-Coll vd., 2012; Sun vd.,2013), motivasyon (Yoon ve Uysal, 2005; Mechinda vd., 2009), benlik uyumu (Bosnjak vd.,2011; Sop, 2013) marka değeri (Bianchi ve Pike, 2011; Myagmarsueren ve Chen, 2011), destinasyon kişiliği (Sop, 2013), turist profili (McDowall, 2010; Özdemir vd., 2012a; Özdemir vd., 2012b; Chi, 2011; Deng ve Pierskalla, 2011; Kılıç,2011; Chi, 2012; Taşçı, 2016) farklı değişkenler üzerinde durmuş olsa da bu çalışmada özellikle turistlerin asıl satın aldıkları turistik ürün olan deneyimler ve bu deneyimler ile oluşturulan sadakatte destinasyon aidiyetinin şart olup olmadığının belirlenmesi amaçlanmaktadır. Bu amaç kapsamında Fethiye'yi ziyaret edenturistlerden anket tekniği kullanılarak birincil veriler elde edilmiş ve sonuçlar paylaşılmıştır. Araştırma, zaman, mekan ve maliyet olarak Fethiye'yi 2016 yılında ziyaret eden 395 turist ile sınırlandırılmıştır.

\section{Literatür Taraması}

Sadakat ile ilgili çalışmalar (Dick ve Basu, 1994; Oliver, 1999; Oppermann 2000; Weber, 2001) önceleri pazarlama ve yönetim literatüründe tekrarlanan satın alma davranışlarını, başkalarına tavsiye etme ve olumlu ağızdan ağza pazarlama faaliyetlerini tanımlamak amacıyla gerçekleştirilmiştir. Daha sonraları ise, turizm alanında da mevcut turistleri elde tutmanın ve sadık turist oluşturmanın önemli bir başarı faktörü olduğu fark edilmiştir (Yoo ve Bai, 2013: 166). Bununla birlikte, destinasyonlar arasında artan rekabet ile farklı pazarlama stratejilerine intiyaç 
duyulması, destinasyonların da diğer ürünler gibi turistlerin tekrar ziyaret edebilecekleri veya diğer potansiyel turistlere tavsiye edebilecekleri bir turistik ürün olarak düşünülmesine neden olmuş ve böylelikle destinasyona yönelik sadakat çalışmaları ortaya çıkmaya başlamış (Lopez-Mosquera ve Sanchez, 2013: 28) ve destinasyon sadakati çalışmaları 1990'ı (Dick ve Basu, 1994; Oliver, 1999) yıllardan beri önem kazanarak günümüzde de uygulayıcılar ve araştırmacılar için dikkat çeken bir konu haline gelmiştir. Sadakat kavramının turizm alanında 90'lı yıllara kadar fazlaca inmal edilmesinin nedenimuhtemelen kavramsal ve metodolojik zorluklar ve uygulamaların karmaşıklığıdır (Lee, Graefe ve Burns, 2007: 464).

Günümüz turizm destinasyonları son yıllarda zorlu rekabet koşulları içinde yaşamlarını devam ettirmek için mücadele vermektedirler. Bu yüzden destinasyon pazarlamacıların "niçin ziyaretçilerin destinasyona sadakat geliştirdiğini" ve "neyin destinasyon sadakatini belirlediğini" daha iyi anlamaları gerekmektedir (Chen ve Gürsoy, 2001: 83). Bununla birlikte, turizm alanındaki önceki çalışmalar daha rekabetçi ve başarılı destinasyonlar meydana getirmek için destinasyon sadakati oluşturmanın ve sürdürmenin destinasyon pazarlamacıları için kritik olacağını göstermiştir (Kim, 2008: 301).

Fiziksel zevk ve toplumsal hayata dayanan (Swarbrooke ve Horner, 2007: 5) turizm deneyimi, "turistler tarafından hissedilen subjektif zihinsel durum" olarak tanımlanmaktadır (Otto ve Ritchie, 1996: 166). Turizm deneyimi anlayışı turistlerin ve ziyaretçilerin kalış süresince yaşadıkları algı ve duyguları tanımaya dayalı potansiyel pazar bölümlendirmesi, konumlandırılması ve tedarik sağlama açısından merkezi bir konudur (Mendes vd., 2010: 112). Destinasyon deneyimi ise konaklama, yiyecek ve içecek ile ilgili hizmetleri ve tecrübeleri ticari bir işlemin bir parçası olarak içeren sıradan uygulamalardan olağandışı anların yaratılmasına ve etkileşim içindeki alanların paylaşımına kadar çeşitli şekillerde ortaya çıkan algı durumu olarak tanımlanabilir (Osman, Johns ve Lugosi, 2014: 239). Başka bir ifade ile destinasyon deneyimi, turistin sınırlı coğrafi bölgede ve sınırlı bir süre boyunca edindiği, sürekli ve birbiriyle bağlantılı hizmetlerdir (Mendes vd., 2010: 112). Pazarlamacılar ve uygulayıcılar, sadakat kavramının iki önemli boyutu olan tekrar ziyaret etme ve başkalarına tavsiye etme niyetlerini kuvvetlendirmek için (Taşkın ve Karadamar, 2016: 201) turistlere benzersiz bir deneyim yaşatmaktadırlar. Benzersiz bir deneyim yaşatılan turistler turistik bir ürün olan destinasyonla kendilerini özel hissederek duygusal bir bağ kurmaktadırlar (Çelik ve Gökçe, 2015: 31). Bu nedenle destinasyonların markalaşması sadece destinasyon pazarlamacılarının, uygulayıcıların ve yöneticilerin pazarlama stratejisi geliştirmeleriyle değil bununla birlikte destinasyonu ziyaret eden turistlerin kendilerini özel hissedecekleri benzersiz bir deneyim yaşamaları ile mümkün hale gelmektedir (Taşkın ve Karadamar, 2016: 200). Bu kapsamda çalışmanın temel hipotezi olan $H_{1}$ : "Destinasyon deneyiminin destinasyon sadakati üzerinde anlamlı ve olumlu etkisi vardır" hipotezi değişkenler arasında destinasyon aidiyetinin aracılık rolünün olup olmadığının belirlenmesinden önce test edilmiştir.

Turizm pazarında giderek artan rekabet, turist sadakatini olumlu yönde etkileyecek ve katkı sağlayabilecek değişkenlerin önemini ortaya çıkarmış ve araştırmacılar destinasyon aidiyeti gibi sadakate öncül davranışların incelenmesine önem vermeye başlamışlardır (Su, Cheng ve Huang, 2011: 2721). Destinasyon sadakatinin oluşumunda öncül olarak kabul edilen (Yüksel vd., 2010) destinasyon aidiyeti bu özelliğinden dolayı turizm pazarlamasını güçlendiren bir kavram olarak görülmektedir (Tsai, 2012: 139). Kyle, Graefe, Manning ve Bacon (2004: 102) tutumsal sadakatin kısmen destinasyon aidiyeti ile benzerlik gösterdiğini belirtmektedir. Araştırmacılar genellikle destinasyon aidiyetini bütünsel sadakati ve daha sonrasında 
da davranışsal sadakati etkileyen ve oluşturan tutumsal sadakatin ortaya çıkarılmasın da önemli bir husus olarak görmüşlerdir. Ziyaretçilerin duyuşşsal satın alma süreçlerini etkileyen destinasyona yönelik kavramsal yapılar turistlerin özel bir bağ ile tekrar ziyaret edecekleri destinasyona yönelik teşvik edici güç durumunda bulunabilir (Su vd., 2011: 2724- 2725). Aidiyet değişkeninin sadakat ile yakın ilişkisi göz önünde bulundurulduğunda kaliteli deneyim elde etmiş turistlerin sadakat oluşum sürecinde aidiyetin bir önkoşul niteliği taşıyacağı düşünülmektedir. $\mathrm{Bu}$ kapsamda ise " $\mathrm{H}_{2}$ :Destinasyon deneyiminin destinasyon sadakati üzerindeki anlamlı ve olumlu etkisinde destinasyon aidiyetinin aracılık etkisi vardır." hipozeti geliştilerek kurulan yapısal eşitlik modeli kapsamında test edilmiştir.

\section{Yöntem}

\subsection{Araştırmanın Amacı ve Önemi}

Son yıllarda sadakat kavramının destinasyon pazarlamasındaki maliyet düşürücü etkisi gibi destinasyon ve destinasyonda faaliyet gösteren işletmelere sunduğu faydalarıyla turizm alanında dikkat çeken bir kavram haline gelmiş ve destinasyon sadakati ile ilgili yerli ve yabancı literatürde birçok çalışma yapılmıştır. Ancak daha önce destinasyon sadakati ile ilgili yapılan çalışmalar incelendiğinde bu çalışmanın yapılmasına da neden oluşturabilecek bazı eksiklikler tespit edilmiştir. Bunlar;

- Destinasyon sadakati oluşumu sürecinde doğrudan ya da dolaylı etki eden değişkenlerin belirlenmesindeki eksiklikler,

- Sadakat kavramının işletme yönüyle daha fazla çalışılıp turizm alanında özellikle de destinasyon temelinde çalışmaların kavramı tam açıklayamadığı,

- Destinasyon sadakatine ulusal yazında yeterli önemin verilmediği ve

- Her ne kadar destinasyon sadakatine doğrudan etki eden değişkenler çalışmalarda yer almış olsa da doğrudan etkilere aracı olan değişkenlerin tam anlamıyla açıklanamadığıdır.

Bu nedenle mevcut modelde (Şekil 1) destinasyon sadakati oluşumu sürecinde kullanılan değişkenler, daha önceki çalışmalar da kullanılan modellerden ve sadakat oluşumu için kullanılan değişkenler arası ilişki yollarından farklı olarak düşünülmüştür. Kurulan yapısal eşitlik modellemesinde destinasyon deneyimi, destinasyon aidiyeti değişkenleri arasında doğrudan ve dolaylı ilişki yolları çizilmiş ve yol analizi ile model test edilmiştir. Bu kapsamda araştırmanın temel amacı; destinasyon pazarlaması kapsamında destinasyon aidiyeti, destinasyon deneyimi ve destinasyon sadakati arasındaki ilişkinin niteliğini açıklamaktır. Ayrıca destinasyon sadakatinin pazarlama alanındaki yeri göz önünde bulundurulduğunda bu çalışma, yerli ve yabancı literatüre sağlayacağı katkı ve destinasyon pazarlaması alanında çalışan araştırmacılara ve sektör uygulayıcılarına sunacağı yönlendirmelerle önem taşıdığı düşünülmektedir.

\subsection{Araştırmanın Modeli ve Hipotezleri}

$\mathrm{Bu}$ çalışmada, destinasyon deneyimi, aidiyeti ve sadakati değişkenleri arasında doğrudan ve dolaylı ilişkilerin varlığına yönelik oluşturulan araştırma modelinde (Şekil 1) destinasyon sadakati oluşum sürecinde doğrudan etki eden destinasyon deneyimi değişkeninin varlığına başka bir takım değişkenlerin aracılık edip etmediği araştırılmaktadır. Bu amaçla araştırma modeli oluşturulurken Baron ve Kenny (1986: 1177)' nin aracılık etkisi ölçmek için belirlediği şartlar takip edilmiştir. Bu şartlar, 
- Bağımsız değişkenin aracı değişkeni etkilemesi gerekmektedir,

- Bağımsız değişken bağımlı değişkeni etkilemelidir,

- Aracı değişken bağımlı değişkeni etkilemelidir.

Araştırma modelinin daha önce yapılan araştırmaların incelenmesi sonucunda Baron ve Kenny (1986)' nin aracılık etki modeli için aranacak şartları sağladığı görülmüştür. Yani destinasyon deneyiminin destinasyon sadakatine yönelik etkisinde destinasyon aidiyetinin aracı etkisi olduğu varsayılabilmektedir. Bu doğrultuda kurulan araştırma modeli aşağıdaki gibidir (Şekil 1).

Şekil 1: Araştırma Modeli

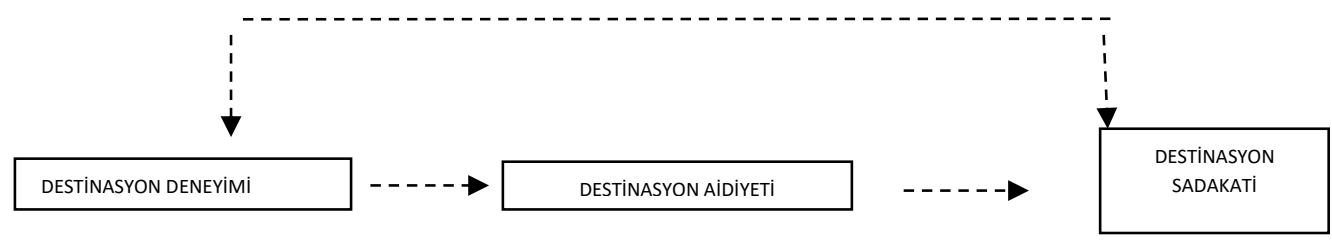

Destinasyon sadakati, destinasyon deneyimi ve destinasyon aidiyeti değişkenlerinin doğrudan ve dolaylı etkileri yapısal eşitlik modellemesi kapsamında aşağıdaki hipotezler ile test edilmiştir;

$\mathbf{H}_{1}$ : Destinasyon deneyiminin destinasyon sadakati üzerinde anlamlı ve olumlu etkisi vardır.

$\mathbf{H}_{2}$ : Destinasyon deneyiminin destinasyon sadakati üzerindeki anlamlı ve olumlu etkisinde destinasyon aidiyetinin aracılık etkisi vardır.

\subsection{Araştırmanın Evreni ve Örneklemi}

Araştırmanın örneklemini Fethiye'de 2016 yılı Nisan-Eylül ayları arasında tatil yapmış yerli ve yabancı turistler oluşturmaktadır. Belirlenen evrenden alınacak örnekler ise olasılığa dayalı olmayan örnekleme yöntemlerinden kolayda örnekleme yöntemi kullanılarak belirlenmiştir. Bu yöntemde araştırmaya dahil olmak isteyen herkesin veri toplama sürecine ve örneğe dahil edilmesi amaçlanmaktadır (Altunışık vd., 2012: 142).

Fethiye'den elde edilmesi gereken örneklem sayısı 2015 yılı Muğla İ Kültür ve Turizm Müdürlüğü'nden ve ilgili kurumun internet sayfasından alınan bilgilere göre belirlenmiştir. Elde edilen bilgilere göre Muğla'yı 2015 yılı Ocak-Ekim ayları arasında ziyaret eden yerli $(158,694)$ ve yabancı $(2,889,234)$ turist sayısı toplam $3,047.928$ 'dir. Fethiye Limanı'ndan giriş yapan yerli $(5,554)$ ve yabancı $(14,245)$ turist sayısı 19,799 'dır. Dalaman Havalimanı'ndan giriş yapan yerli $(17,378)$ ve yabancı $(1,584,609)$ turist sayısı 1,601,987'dır. Bodrum-Milas Havalimanı'ndan giriş yapan yerli $(17,593)$ ve yabancı $(796,929)$ turist sayısı 814,522'dır (www.muglakulturturizm.gov.tr). Muğla ilini ziyaret eden turistler içinde Fethiye destinasyonun payı, Fethiye Limanı'nın yanı sıra havalimanlarını kullanarak Fethiye'ye giriş yapan turistler ile karayolunu kullanarak gelen turistler düşünüldüğünde Fethiye'yi ziyaret eden yerli ve yabancı turistlerin sayısının en az 100.000'ni aşmış olacağı düşünülmektedir. Bu doğrultuda evreni \% 95 güven düzeyinde temsil edecek denek sayısı en az 384 olarak belirlenmiştir (Ural ve Kılıç, 2006: 49). 


\subsection{Veri Toplama Aracı ve Süreci}

Fethiye'de tatil yapan yerli ve yabancı turistlerin destinasyona yönelik duygusal, duyusal fiziksel ve entelektüel deneyim algılarını belirlemeye yönelik Brakus, Schmitt ve Zarantonello (2009)'un marka deneyimini ölçmek amacıyla geliştirdikleri 12 maddelik ölçek, Fethiye'nin destinasyon aidiyetinin belirlenmesi amacıyla Veasna, Wu ve Huang (2013)'ın destinasyon aidiyetini ölçmek için kullandığı 8 maddelik ölçek ve Fethiye'ye yönelik sadakatin tespit edilmesinde Sırakaya-Türk vd., (2015)'in destinasyon sadakatini ölçmeye yönelik kullandıkları 9 maddelik ölçek kullanılmıştır.

Saha araştırmasına başlanmadan önce anket formunda oluşabilecek hataların önüne geçmek ve cevaplayıcılar açısından herhangi bir anlama sıkıntısının ve incitici ifadelerin olup olmadığı belirlemek, anketin ortalama doldurulma süresini ayarlamak, cevaplayıcıların işaretlemek istemedikleri herhangi bir ifadenin var olup olmadığını tespit etmek ve hangi ifadelerin gereksiz olup olmadığını görmek amacıyla (Altunışık vd., 2012: 137) Fethiye'yi 2015 yılı Temmuz-Ağustos aylarında ziyaret eden 30 yerli ve 28 yabancı turistle ön uygulama gerçekleştirilmiştir. Ön uygulama sonucunda anket formu son halini almıştır. Ön uygulama da kullanılan ölçeklerin (Destinasyon Aidiyeti, Destinasyon Deneyimi ve Destinasyon Sadakati)sosyal bilimler alanında yüksek güvenilirliğe sahip olduğu sonucuna varılmış (Kayış, 2009: 405) ve sonuçlar Tablo 1'de verilmiştir.

\section{Tablo 1: Araştırmada Kullanılan Ölçeklerin Ön Uygulama Güvenilirlik Sonucu}

\begin{tabular}{|c|c|c|}
\hline Ölçekler & Güvenilirlik ( $\alpha$ ) & Soru Sayısı \\
\hline Destinasyon Aidiyeti & 0,868 & 8 \\
\hline Destinasyon Deneyimi & 0,812 & 12 \\
\hline Destinasyon Sadakati & 0,816 & 9 \\
\hline
\end{tabular}

Araştırma verilerinin elde edilmesinde kullanılacak olan ankete son hali verildikten sonra anketler, Fethiye'de 2016 yılı Nisan-Eylül ayları arasında tatil yapan turistlere uygulanmış ve gerekli tüm etik kurallara uyularak toplamda 452 anket elde edilmiştir. Cevaplayıcılar tarafından doldurulmuş anket formlarının incelenmesi sonucu 57 anketin eksik doldurulmuş veya geçersiz olduğu görülmüş ve analiz dışı bırakılmıştır. Geriye kalan 395 anket formu araştırmanın amaçları ve bu doğrultudaki hipotezler kapsamında istatistiksel analizlere tabi tutulmuştur.

\section{5. Öıçeklere Uygulanan Doğrulayıcı Faktör Analizleri}

Araştırma kapsamında kullanılan ölçeklerin başka kültürlerde ve örneklemlerde geliştirilmiş olmasından dolayı geçerliliklerinin doğrulanması gerekmektedir (Bayram, 2013: 42; Seçer, 2015:171). Bu amaçla araştırmada kullanılan her bir ölçeğe doğrulayıcı faktör analizi (DFA) uygulanmıştır. 


\section{Şekil 2: Destinasyon Aidiyeti Ölçeği Doğrulayıcı Faktör Analizi Modeli}

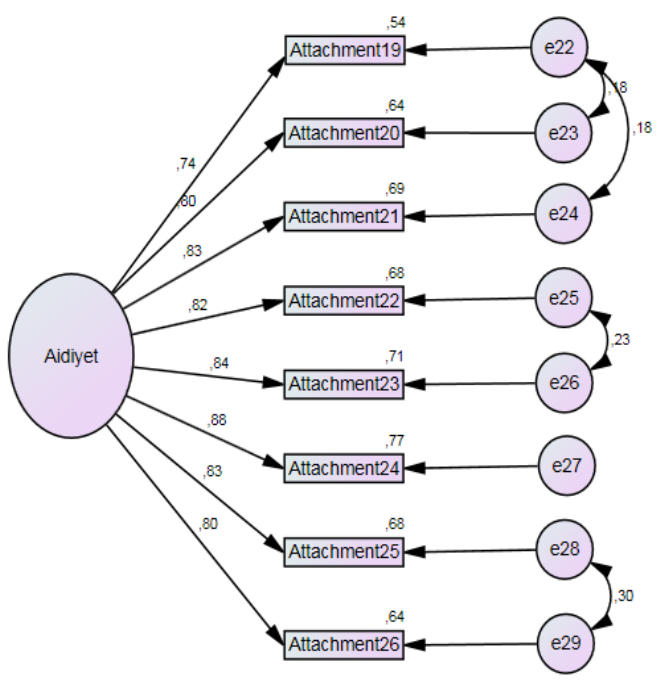

Araştırmada önerilen modelin iyi uyum ve kabul edilebilir uyum değer aralıkları (Schermelleh-Engel, Moosbrugger ve Müller, 2003: 52) ile destinasyon aidiyeti ölçeği modelinin gösterdiği uyum değerleri verilmiştir. Tablo 2'de verilen uyum değerleri doğrultusunda destinasyon aidiyeti ölçeği modeli uyum değerleri "kabul edilebilir uyum" değerleri ( $x^{2} / d f$, RMSEA) ve "iyi uyum" değerlerini (NFI, CFI, GFI ve AGFI) göstermektedir.

Tablo 2: Destinasyon Aidiyeti Ölçeği Doğrulayıcı Faktör Analizi Model Uyum Değerleri

\begin{tabular}{l|c|c|c}
$\begin{array}{l}\text { Uyum } \\
\text { Ölçüleri }\end{array}$ & $\begin{array}{c}\text { İyi Uyum } \\
\text { Değerleri }\end{array}$ & $\begin{array}{c}\text { Kabul Edilebilir Uyum } \\
\text { Değerleri }\end{array}$ & $\begin{array}{c}\text { Ölçek Uyum } \\
\text { Değerleri }\end{array}$ \\
\hline $\mathbf{X}^{2} / \mathbf{d f}$ & $0 \leq \mathrm{X}^{2} / \mathrm{df} \leq 2$ & $2<\mathrm{X}^{2} / \mathrm{df} \leq 3$ & 2,756 \\
\hline RMSEA & $0 \leq \mathrm{RMSEA} \leq, 05$ &, $05<\mathrm{RMSEA} \leq, 08$ & 0,067 \\
\hline NFI & $, 95 \leq \mathrm{NFI} \leq 1,00$ &, $90 \leq \mathrm{NFI}<, 95$ & 0,983 \\
\hline CFI & $, 97 \leq \mathrm{CFI} \leq 1,00$ &, $95 \leq \mathrm{CFI}<, 97$ & 0,989 \\
\hline GFI & $, 95 \leq \mathrm{GFI} \leq 1,00$ &, $90 \leq \mathrm{GFI}<, 95$ & 0,973 \\
\hline AGFI & $, 90 \leq \mathrm{AGFI} \leq 1,00$ &, $85 \leq \mathrm{AGFI}<, 90$ & 0,940
\end{tabular}

Kaynak: Schermelleh-Engel, Karin, Moosbrugger, Helfried ve Müller, Hans (2003). "Evaluating the Fit of Structural Equation Models: Test of Significance and Descriptive Goodness-of-Fit Measures" [Yapısal Eşitlik Modellerinin Uyum Değerlendirmesi: Anlamlılık ve Uyum İyiliği Ölçümleri]. Methods of Psychological Research Online, 8 (2), 23-74.

DFA yapılan destinasyon aidiyeti ölçeğinin faktör yükleri 0,50 değerin üstündedir ve ölçek güvenilirliği ise 0,944 olarak belirlenmiştir.

Destinasyon deneyimi ölçeğine uygulanan DFA modeli ise Şekil 3' de gösterilmektedir. Ölçekteki "Fethiye benim duyularım (görsel, işitsel vb.) üzerinde güçlü bir etkiye sahiptir (Experience27)", "Fethiye'yi duyusal olarak ilginç buluyorum (Experience28)", "Fethiye duyularıma cazip gelmiyor (Experience29)" ve "Fethiye faaliyet odaklı değildir (Experience35)" ifadelerinin faktör yüklerindeki düşüklük ve model uyum değerlerine yönelik olumsuz etkisinden dolayı analiz dışı bırakılmıştır. Ölçekteki ifadeler çıkarıldıktan sonra gerçekleştirilen DFA'da ölçek uyum değerlerinin 
en az kabul edilebilir uyum değerleri aralığında olduğu görülmüş ve bu nedenle ifadeler arası herhangi bir modifikasyona başvurulmamıştır.

\section{Şekil 3: Destinasyon Deneyimi Ölçeği Doğrulayıcı Faktör Analizi Model}

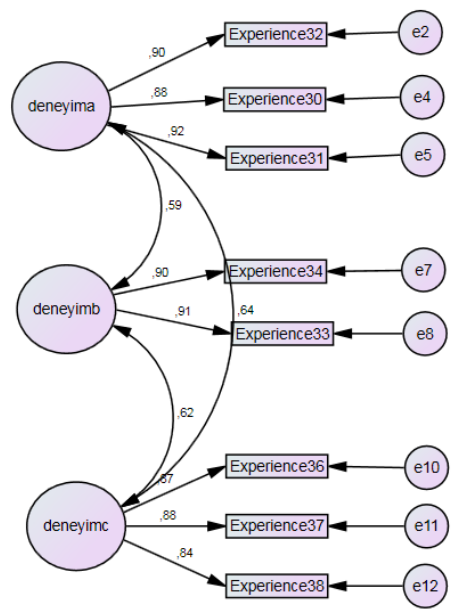

Destinasyon deneyimi ölçeğine yönelik yapılan DFA sonuçları uyum değerleriaşağıdaverilmiştir. Tablo 4'e göre model uyum değerleri "kabul edilebilir uyum" değerleri ( $x^{2} / \mathrm{df}$, RMSEA) ve "iyi uyum" değerlerini (NFI, CFI, GFI ve AGFI) göstermektedir.

Tablo 4: Destinasyon Deneyimi Ölçeği Doğrulayıcı Faktör Analizi Model Uyum Değerleri

\begin{tabular}{l|c|c|c}
$\begin{array}{l}\text { Uyum } \\
\text { Ölçüleri }\end{array}$ & $\begin{array}{c}\text { İyi Uyum } \\
\text { Değerleri }\end{array}$ & $\begin{array}{c}\text { Kabul Edilebilir Uyum } \\
\text { Değerleri }\end{array}$ & $\begin{array}{c}\text { Ölçek Uyum } \\
\text { Değerleri }\end{array}$ \\
\hline $\mathbf{X}^{2} / \mathbf{d f}$ & $0 \leq \mathrm{X}^{2} / \mathrm{df} \leq 2$ & $2<\mathrm{X}^{2} / \mathrm{df} \leq 3$ & 2,516 \\
\hline RMSEA & $0 \leq \mathrm{RMSEA} \leq, 05$ &, $05<\mathrm{RMSEA} \leq, 08$ & 0,062 \\
\hline NFI & $, 95 \leq \mathrm{NFI} \leq 1,00$ &, $90 \leq \mathrm{NFI}<, 95$ & 0,983 \\
\hline CFI & $, 97 \leq \mathrm{CFI} \leq 1,00$ &, $95 \leq \mathrm{CFI}<, 97$ & 0,989 \\
\hline GFI & $, 95 \leq \mathrm{GFI} \leq 1,00$ &, $90 \leq \mathrm{GFI}<, 95$ & 0,974 \\
\hline AGFI & $, 90 \leq \mathrm{AGFI} \leq 1,00$ &, $85 \leq \mathrm{AGFI}<, 90$ & 0,944
\end{tabular}

Kaynak: Schermelleh-Engel, Karin, Moosbrugger, Helfried ve Müller, Hans (2003). "Evaluating the Fit of Structural Equation Models: Test of Significance and Descriptive Goodness-of-Fit Measures" [Yapısal Eşitlik Modellerinin Uyum Değerlendirmesi: Anlamlılık ve Uyum İyiliği Ölçümleri]. Methods of Psychological Research Online, 8 (2), 23-74.

Destinasyon deneyimi ölçeğinin DFA sonucundaki faktör yüklerinin 0,50 değerin üstünde olduğu görülmüştür. Analizde çıkarılan ifadelerden sonra boyut ve ölçek bazında test edilen güvenilirlik değerleri de ölçeğin sosyal bilimler alanında yüksek güvenilirlik düzeyine sahip olduğunu göstermektedir. Uygulanan DFA ve güvenilirlik analizi sonucunda ölçek boyutlarına verilen isimler tekrardan değerlendirilmiş ve boyutlar "1. Boyut: Duygusal (Cronbach Alpha: 0,924)", "2. Boyut: Davranışsal (Cronbach Alpha: 0,900)", "3. Boyut: Entellektüel (Cronbach Alpha: 0,893)" olarak isimlendirilmiştir. DFA sonucunda destinasyon deneyimi ölçeğinin güvenilirliği ise 0,910 olarak belirlenmiştir. 
Son olarak DFA destinasyon sadakati ölçeğine uygulanmıştır. Ölçeğin uyum değerleri en az kabul edilebilir uyum değerleri aralığında yer alması amacıyla DFA modelindeki ifadeler arası önerilen modifikasyonlara (e7-e8 / e8-e9) başvurulmuştur (Şekil 4).

\section{Şekil 4: Destinasyon Sadakati Ölçeği Doğrulayıcı Faktör Analizi Modeli}

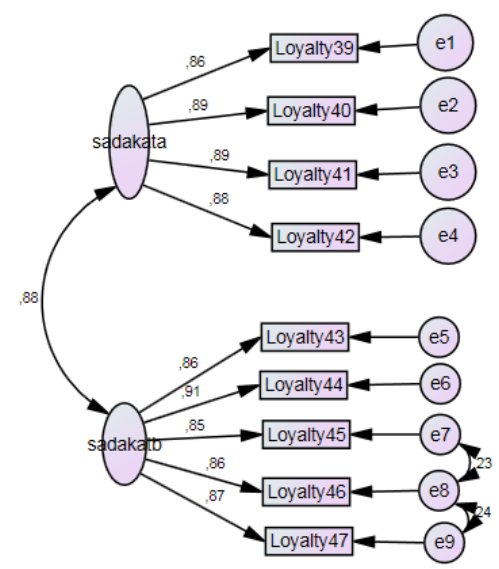

Destinasyon sadakati ölçeğine yönelik yapılan DFA sonuçları uyum değerleri aşağıdaki verilmiştir. Tablo 5'e göre model uyum değerleri "kabul edilebilir uyum" değerleri ( $x^{2} / \mathrm{df}$, RMSEA) ve "iyi uyum" değerlerini (NFI, CFI, GFI ve AGFI) göstermektedir.

\section{Tablo 5: Destinasyon Sadakati Ölçeği Doğrulayıcı Faktör Analizi Model Uyum} Değerleri

\begin{tabular}{l|c|c|c}
$\begin{array}{l}\text { Uyum } \\
\text { Ölçüleri }\end{array}$ & $\begin{array}{c}\text { İyi Uyum } \\
\text { Değerleri }\end{array}$ & $\begin{array}{c}\text { Kabul Edilebilir Uyum } \\
\text { Değerleri }\end{array}$ & $\begin{array}{c}\text { Ölçek Uyum } \\
\text { Değerleri }\end{array}$ \\
\hline $\mathbf{X}^{2} /$ df & $0 \leq \chi^{2} / \mathrm{df} \leq 2$ & $2<\mathrm{X}^{2} / \mathrm{df} \leq 3$ & 2,518 \\
\hline RMSEA & $0 \leq \mathrm{RMSEA} \leq, 05$ &, $05<\mathrm{RMSEA} \leq, 08$ & 0,062 \\
\hline NFI & $, 95 \leq \mathrm{NFI} \leq 1,00$ &, $90 \leq \mathrm{NFI}<, 95$ & 0,983 \\
\hline CFI & $, 97 \leq \mathrm{CFI} \leq 1,00$ &, $95 \leq \mathrm{CFI}<, 97$ & 0,990 \\
\hline GFI & $, 95 \leq \mathrm{GFI} \leq 1,00$ &, $90 \leq \mathrm{GFI}<, 95$ & 0,968 \\
\hline AGFI & $, 90 \leq \mathrm{AGFI} \leq 1,00$ &, $85 \leq \mathrm{AGFI}<, 90$ & 0,940
\end{tabular}

Kaynak: Schermelleh-Engel, Karin, Moosbrugger, Helfried ve Müller, Hans (2003). "Evaluating the Fit of Structural Equation Models: Test of Significance and Descriptive Goodness-of-Fit Measures" [Yapısal Eşitlik Modellerinin Uyum Değerlendirmesi: Anlamlılık ve Uyum İyiliği Ölçümleri]. Methods of Psychological Research Online, 8 (2), 23-74.

DFA yapılan destinasyon sadakati ölçeğinin faktör yükleri 0,50 değerin üstündedir. Uygulanan DFA ve güvenilirlik analizi sonucunda ölçek boyutlarına verilen isimler tekrar gözden geçirilmiş ve daha önce uygulanan AFA sonucundaki isimlendirme ile aynı şekilde, 1. Boyut: Başkalarına Tavsiye Etme Niyeti (C. Alpha: 0,943) ve 2. Boyut: Tekrar Ziyaret Etme Niyeti (C. Alpha: 0,931) olarak isimlendirilmiştir. DFA sonucundaki destinasyon sadakati ölçek güvenilirliği ise 0,958 olarak belirlenmiştir. 


\section{Bulgular}

\subsection{Ziyaretçilere Yönelik Demografik Bulgular}

Araştırmaya katılan ziyaretçilerin demografik özelliklerine ilişkin bulgular Tablo 6' da gösterilmektedir.

Tablo 6: Ziyaretçilerin Demografik Özellikleri

\begin{tabular}{l|l|l}
$\begin{array}{l}\text { Ziyaretçilerin } \\
\text { Cinsiyeti } \\
\text { (N:395, \% 100) }\end{array}$ & $\mathbf{n}$ & $\%$ \\
\hline Erkek & 198 & 50,1 \\
Kadın & 197 & 49,9 \\
\hline $\begin{array}{l}\text { Ziyaretçilerin } \\
\text { Yaşları } \\
\text { (N:395, \% 100) }\end{array}$ & $\mathbf{n}$ & $\%$ \\
\hline $18-24$ & & \\
$25-31$ & 136 & 34,4 \\
$32-38$ & 72 & 18,2 \\
39-45 & 58 & 14,7 \\
46-52 & 54 & 13,7 \\
53-59 & 38 & 9,6 \\
60 ve üzeri & 26 & 6,6 \\
\hline Ziyaretçilerin Eğitim & 11 & 2,8 \\
$\begin{array}{l}\text { durumu } \\
\text { (N:395, \% 100) }\end{array}$ & $\mathbf{n}$ & $\%$ \\
\hline $\begin{array}{l}\text { İlköğretim } \\
\text { Ortaöğretim }\end{array}$ & 15 & 3,8 \\
Lisans & 108 & 27,3 \\
Yüksek Lisans & 197 & 49,9 \\
Doktora & 65 & 16,5 \\
& 10 & 2,5
\end{tabular}

\begin{tabular}{l|l|l}
$\begin{array}{l}\text { Ziyaretçilerin } \\
\text { Uyrukları } \\
\text { (N:395, \% 100) }\end{array}$ & $\mathbf{n}$ & $\%$ \\
\hline $\begin{array}{l}\text { T.C. } \\
\text { Ingiltere }\end{array}$ & 197 & 49,9 \\
Almanya & 42 & 29,4 \\
Ukrayna & 18 & 4,6 \\
Diğer & 22 & 6,5 \\
\hline Ziyaretçilerin Aylık & & \\
gelir & $\mathbf{n}$ & $\%$ \\
(N:395, \% 100) & & \\
\hline 1001-1500 TL & 42 & 10,6 \\
1501-2000 TL & 59 & 14,9 \\
2001-2500 TL & 46 & 11,6 \\
2501-3000 TL & 46 & 11,6 \\
3001-3500 TL & 58 & 14,7 \\
3501-4000 TL & 30 & 7,6 \\
4001-4500 TL & 15 & 3,8 \\
4501-5000 TL & 37 & 9,4 \\
5001 TL ve üzeri & 62 & 15,7 \\
\hline $\begin{array}{l}\text { Ziyaretçilerin Medeni } \\
\text { durumu(N:395, \% 100) }\end{array}$ & $\mathbf{n}$ & $\%$ \\
\hline Bekar & 217 & 54,9 \\
Evli & 178 & 45,1 \\
& &
\end{tabular}

Fethiye'de tatil yapan ziyaretçilerin \% 50,1'i erkek, \% 49,9'u ise kadındır. \%34,4'ü 18-24 yaş aralığında yer alan gençlerden oluşmaktadır. Araştırmada \% 54,9 bekar ve \%45,1 evli birey yer almaktadır. Ziyaretçiler ağırlıklı olarak lisans mezunudur (\%: 49,9). Eğitim durumunu gösteren geriye kalan \% 51,1'lik oranı sırasıyla ortaöğretim, yüksek lisans, ilköğretim ve doktora mezunları oluşturmaktadır. Katılımcılar milliyetlerine göre ayrıldığında en fazla payı (\%: 49,9) Türkiye Cumhuriyeti vatandaşları oluşturmakta, bu oranı İngilizler (\%: 29,4), Almanlar (\%: 10,6) ve Ukraynalılar (\% 4,6) takip etmektedir. Diğer ziyaretçiler ise; Amerika (\% 1,8), Belçika $(\%$ 1), Fransa (\% 1), Rusya, (\% 0,8), Belarus (\% 0,5), ve Hollanda $(\% 0,5)$ vatandaşlarıdır. Ziyaretçilerin gelir dağılımına bakıldığında gelir grubunu, her ne kadar en yüksek oran 5001 ve üzeri gelir grubuna sahip ziyaretçiler oluştursa da $(\%: 15,7)$ diğer gelir grubundan bireyleri de hemen hemen yakın oranlarda görmek mümkündür (Tablo 6).

\section{2. İlişkisel Analizler}

Baron ve Kenny (1986: 1177) aracı etkinin var olduğunu söyleyebilmek için bağımlı ve bağımsız değişken arasında var olan doğrudan etkinin, aracı değişken ilave edildiğinde düşmesi ya da anlamsız hale dönüşmesi gerektiğini ifade etmektedir. Bu doğrultuda kurulan aracılı modellerde önce bağımlı ve bağımsız değişken arasındaki 
ilişkidoğrudan etki test edilmiş daha sonra modele aracı değişken eklenip doğrudan olan etkide herhangi bir azalmanın olup olmadığı veya anlamsız $(>0,05)$ hale dönüşüp dönüşmediğine bakılmıştır. Doğrudan ve dolaylı etkileri test etmek amacıyla aşağıdaki modeller kurulmuş ve analize tabi tutulmuştur.

Şekil 5'te gösterilen modelde destinasyon deneyiminin destinasyon sadakati üzerineanlamlı bir etkisinin olup olmadığı test edilmiştir. Kurulan modelin uyum değerleri incelendiğinde model değerlerinin "kabul edilebilir" (X2/df, RMSEA) ve "iyi uyum" (NFI, CFI, GFI, AGFI) değerleri aralığında olduğu görülmüştür (Tablo 7).

\section{Tablo 7: Destinasyon Deneyimi ve Destinasyon Sadakati Arasındaki İlişkiyi Gösteren Modelin Uyum Değerleri}

\begin{tabular}{l|c|c|c}
$\begin{array}{l}\text { Uyum } \\
\text { Ölçüleri }\end{array}$ & $\begin{array}{c}\text { İyi Uyum } \\
\text { Değerleri }\end{array}$ & $\begin{array}{c}\text { Kabul Edilebilir Uyum } \\
\text { Değerleri }\end{array}$ & $\begin{array}{c}\text { Model Uyum } \\
\text { Değerleri }\end{array}$ \\
\hline $\mathbf{X}^{2} /$ df & $0 \leq \mathrm{X}^{2} / \mathrm{df} \leq 2$ & $2<\mathrm{X}^{2} / \mathrm{df} \leq 3$ & 2,128 \\
\hline RMSEA & $0 \leq \mathrm{RMSEA} \leq, 05$ &, $05<\mathrm{RMSEA} \leq, 08$ & 0,054 \\
\hline NFI & $, 95 \leq \mathrm{NFI} \leq 1,00$ &, $90 \leq \mathrm{NFI}<, 95$ & 0,994 \\
\hline CFI & $, 97 \leq \mathrm{CFI} \leq 1,00$ &, $95 \leq \mathrm{CFI}<, 97$ & 0,997 \\
\hline GFI & $, 95 \leq \mathrm{GFI} \leq 1,00$ &, $90 \leq \mathrm{GFI}<, 95$ & 0,991 \\
\hline AGFI & $, 90 \leq \mathrm{AGFI} \leq 1,00$ &, $85 \leq \mathrm{AGFI}<, 90$ & 0,967
\end{tabular}

Kaynak: Schermelleh-Engel, Karin, Moosbrugger, Helfried ve Müller, Hans (2003). "Evaluating the Fit of Structural Equation Models: Test of Significance and Descriptive Goodness-of-Fit Measures" [Yapısal Eşitlik Modellerinin Uyum Değerlendirmesi: Anlamlılık ve Uyum lyiliği Ölçümleri]. Methods of Psychological Research Online, 8 (2), 23-74.

Araştırmada doğrudan ilişkiyi belirlemeye yönelik yapılan destinasyon deneyiminin destinasyon sadakati üzerine etkisini belirlemeye yönelik kurulan model aşağıdaki şekilde gösterilmiştir. Şekil 5'de gösterilen modelin varsayımı destinasyon deneyiminin destinasyon sadakati üzerine etkisi olduğu yönündedir.

\section{Şekil 5: Destinasyon Deneyimi ve Destinasyon Sadakati Arasındaki Doğrudan İlişki Modeli}

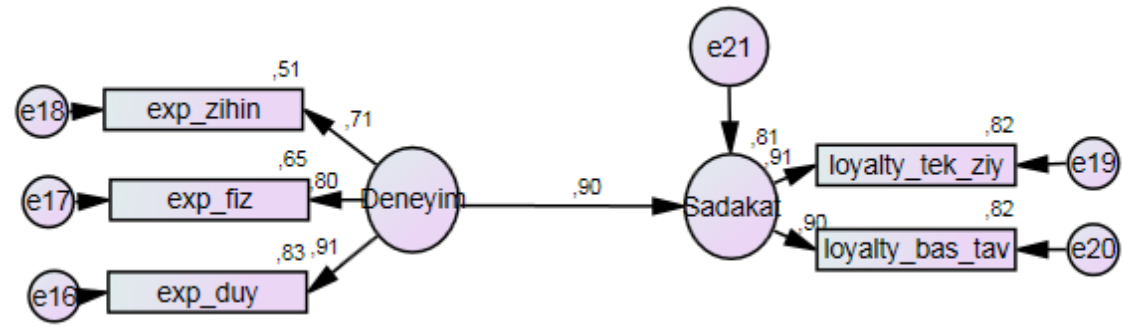

Yapılan analizler destinasyon deneyiminin destinasyon sadakati üzerine etkisinin 0,899 düzeyinde ve anlamlı $(0,000)$ olduğunu göstermiştir (Tablo 8). Elde edilen bu sonuçlar destinasyon deneyiminin destinasyon sadakatine anlamlı ve doğrudan etki ettiğini göstermektedir. Bu doğrultuda araştırma kapsamında geliştirilen "Destinasyon deneyiminin destinasyon sadakati üzerinde anlamlı ve olumlu etkisi vardır $\left(\mathbf{H}_{\mathbf{1}}\right)$." hipotezi kabul edilmiştir. 
Tablo 8: Destinasyon Deneyimi ve Destinasyon Sadakati Arasındaki Doğrudan İlişki Sonucu

\begin{tabular}{l|c|l} 
Modeller & $\begin{array}{l}\text { Standardize Edilmiş } \\
\text { Regresyon } \\
\text { Katsayıları }\end{array}$ & Anlamlılık \\
\cline { 3 - 3 } Deneyrudan Etkiler \\
\hline Sadakat & 0,900 & 0,000
\end{tabular}

Destinasyon sadakatinin oluşmasında destinasyon deneyiminin ve destinasyon aidiyetinin etkisini belirlemek amacıyla Şekil 6'da gösterilen yol analizi çizilmiştir. Kurulan modelin uyum değerleri incelendiğinde "kabul edilebilir" (X2/df, RMSEA, GFI) ve "iyi uyum" (NFI,CFI, AGFI) değerlerini gösterdiği görülmüştür (Tablo 9).

Tablo 9: Destinasyon Deneyimi, Destinasyon Aidiyeti ve Destinasyon Sadakati Arasındaki Dolaylı İlişkiyi Gösteren Modelin Uyum Değerleri

\begin{tabular}{l|c|c|c}
$\begin{array}{l}\text { Uyum } \\
\text { Ölçüleri }\end{array}$ & $\begin{array}{c}\text { İyi Uyum } \\
\text { Değerleri }\end{array}$ & $\begin{array}{c}\text { Kabul Edilebilir } \\
\text { Uyum Değerleri }\end{array}$ & $\begin{array}{c}\text { Model Uyum } \\
\text { Değerleri }\end{array}$ \\
\hline $\mathbf{X}^{2} /$ df & $0 \leq \mathrm{X}^{2} / \mathrm{df} \leq 2$ & $2<\mathrm{X}^{2} / \mathrm{df} \leq 3$ & 2,942 \\
\hline RMSEA & $0 \leq \mathrm{RMSEA} \leq, 05$ &, $05<\mathrm{RMSEA} \leq, 08$ & 0,070 \\
\hline NFI & $, 95 \leq \mathrm{NFI} \leq 1,00$ &, $90 \leq \mathrm{NFI}<, 95$ & 0,962 \\
\hline CFI & $, 97 \leq \mathrm{CFI} \leq 1,00$ &, $95 \leq \mathrm{CFI}<, 97$ & 0,974 \\
\hline GFI & $, 95 \leq \mathrm{GFI} \leq 1,00$ &, $90 \leq \mathrm{GFI}<, 95$ & 0,936 \\
\hline AGFI & $, 90 \leq \mathrm{AGFI} \leq 1,00$ &, $85 \leq \mathrm{AGFI}<, 90$ & 0,901
\end{tabular}

Kaynak: Schermelleh-Engel, Karin, Moosbrugger, Helfried ve Müller, Hans (2003). "Evaluating the Fit of Structural Equation Models: Test of Significance and Descriptive Goodness-of-Fit Measures" [Yapısal Eşitlik Modellerinin Uyum Değerlendirmesi: Anlamlılık ve Uyum İyiliği Ölçümleri]. Methods of Psychological Research Online, 8 (2), 23-74.

Şekil 6'da destinasyon deneyimi, destinasyon aidiyeti ve destinasyon sadakati arasında kurulan modele yönelik standardize edilmiş yol değerleri verilmiştir. Buna göre destinasyon deneyiminde gerçekleşen 1 birim artış destinasyon aidiyetinin 0,810 birimlik artışını sağlayacaktır. Destinasyon aidiyetinin 1 birim artması da destinasyon sadakatinin 0,453 birimlik artmasını sağlayacaktır. Bununla birlikte destinasyon deneyimindeki 1 birimlik artışı da destinasyon sadakatini 0,528 birimlik artmasını sağlayacaktır (Tablo 10). 


\section{Şekil 6: Destinasyon Deneyimi, Destinasyon Aidiyeti ve Destinasyon Sadakati Arasındaki Dolaylı İlişki Modeli}

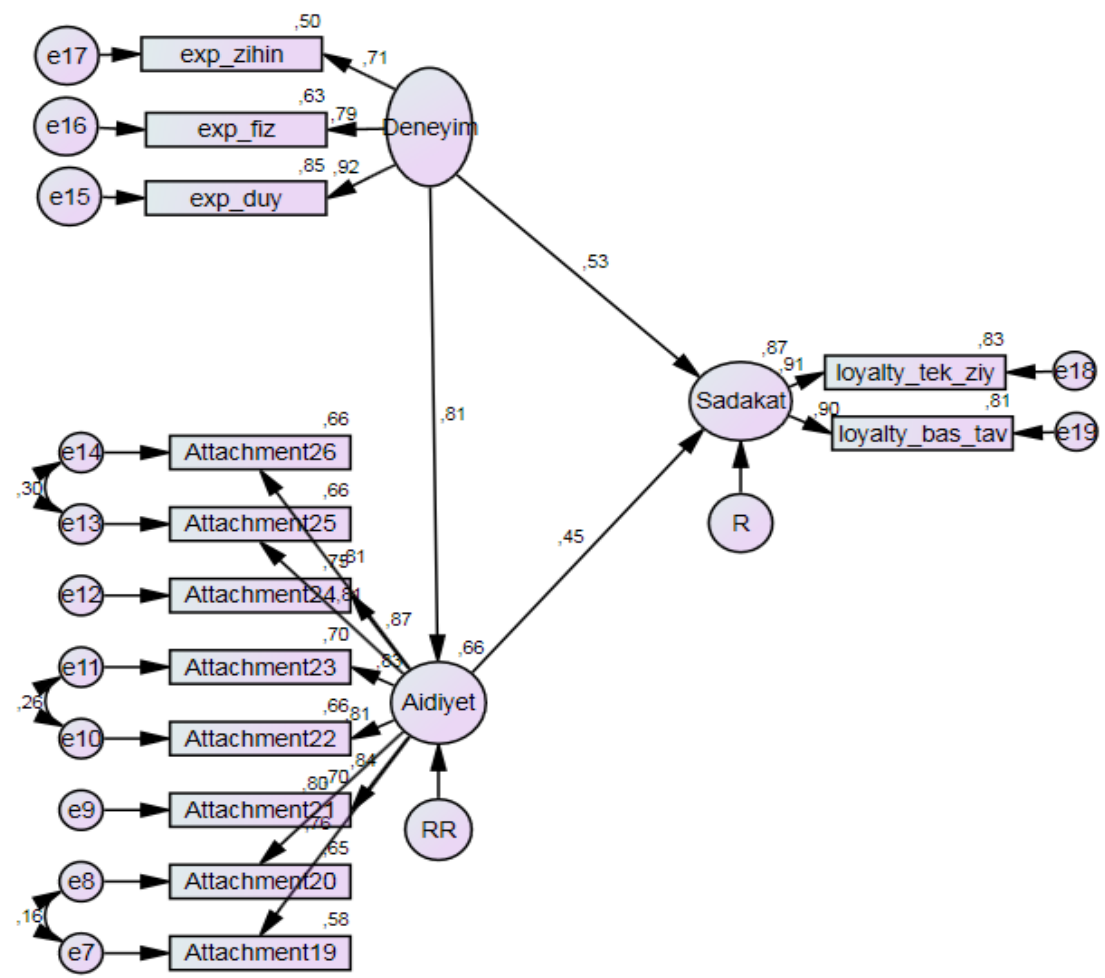

Destinasyon aidiyetinin aracılık etkisi incelendiğinde önce destinasyon deneyiminin destinasyon sadakati üzerindeki etki değerine bakılmıştır. Daha sonra modele destinasyon aidiyeti değişkeni ilave edilip model tekrar çalıştırılmıştır. Değişkenler (destinasyon deneyimi ve destinasyon sadakati) arası doğrudan etki değeri 0,899 ve anlamlılık düzeyi 0,000 (Tablo 8) iken aracı değişken (destinasyon aidiyeti) modele ilave edildiğinde (Şekil 6) destinasyon deneyiminin destinasyon sadakati üzerindeki doğrudan etkisi 0,528 'e düşmüş, doğrudan etki anlamlılık değeri 0,004 ve dolaylı etki anlamlılık değeri 0,001 olarak bulunmuştur (Tablo 10). Her iki anlamlılık değeri 0,05 değerin altında olduğu için model kapsamında doğrudan ve dolaylı etki değerlerinin anlamlılık gösterdiği gözlemlenmiştir. Bu sonuçlar destinasyon deneyiminin destinasyon sadakati üzerindeki etkisinde destinasyon aidiyetinin kısmi aracı rolü olduğunu göstermektedir. Bu hususta "Destinasyon deneyiminin destinasyon sadakati üzerindeki etkisinde destinasyon aidiyetinin aracı rolü vardır $\left(\mathbf{H}_{2}\right)$ " hipotezi kabul edilmiştir.

Tablo 10: Destinasyon Deneyimi, Destinasyon Aidiyeti ve Destinasyon Sadakati Arasındaki Dolaylı İlişki Sonucu

Modeller

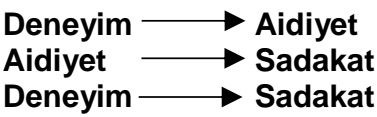

Standardize Edilmiş Regresyon Katsayıları

0,810

0,453

0,528

\begin{tabular}{cc}
\multicolumn{2}{c}{ Anlamlılık } \\
$\begin{array}{c}\text { Doğrudan } \\
\text { Etkiler }\end{array}$ & Dolaylı Etkiler \\
0,004 & \\
0,001 & ------ \\
0,003 & ----- \\
& 0,001
\end{tabular}




\section{Sonuç ve Öneriler}

Gelen turistlerin tekrar aynı destinasyonu ziyaret etmeleri ve ziyaret ettikleri destinasyonu başkalarına tavsiye etmeleri ile meydana gelen destinasyon sadakati hizmet kalitesi, memnuniyet, tatil deneyimi, destinasyon imajı, aidiyet, bilinirlik, algılanan değer, motivasyon, benlik uyumu, marka değeri, destinasyon kişiliği ve turist profili değişkenleri tarafından etkilendiği daha önce yapılan çalışmalarla bu etkileşim ortaya koyulmuştur. Ancak sorun, bu değişkenler arasında ortaya çıkarılan ilişkinin gerçekte kısmi ya da tam olarak başka bir değişkenin varlığına bağlı olup olmadığının henüz tam anlamıyla ortaya çıkarılmamış olmasıdır. Bu da varlığı ortaya çıkarılan ilişkinin dışında başka bir durumun varlığının keşfedilmesi anlamına gelmektedir. Bu keşif sayesinde destinasyon sadakatini etkileyen değişkenlere imkan sunan aracı değişkenler ortaya çıkarılarak destinasyon sadakati oluşum süreci daha dikkatli bir şekilde ele alınacaktır.

$\mathrm{Bu}$ amaçla gerçekleştirilen çalışmada destinasyon sadakat modeli geliştirilerek ilgili literatürün taranması sonucunda önemli görülen değişkenler (destinasyon deneyimi, ve aidiyeti) arasında kurulan yapısal eşitlik modelinde doğrudan ve dolaylı etkiler belirlenmeye çalışılmıştır. Diğer bir değişle evrende zaten var olduğu düşünülen deneyim ve sadakat ilişkisinde destinasyon aidiyetinin kısmi ya da tam bir aracı rol oynayıp oynamadığı belirlenmiştir.

Bu kapsamda çizilen araştırma modeli (Şekil 1) söz konusu değişkenler arasındaki varsayılan ilişkiyi göstermekte ve çalışmanın amaçlarını daha açık bir şekilde ifade etmektedir. Şekil 1'de ilgili literatür kapsamında kurulan ve incelenmek istenen ilk ilişki destinasyon deneyimi ile destinasyon sadakati arasındaki ilişkidir. Türkiye'de önde gelen yaz turizmi merkezlerinden biri olan Fethiye'den elde edilen veriler aracılığıyla yapısal eşitlik modellemesi kurularak incelenen ilişki, literatürün de desteklediği üzere destinasyon deneyiminin destinasyon sadakati üzerinde olumlu etkisi olduğu yönündedir. Bu sonuç Kim ve Brown (2012), San Martin vd., (2013) ve Wu (2016)'nun deneyim sadakat arasındaki ilişkiyi belirlemeye yönelik yaptığı çalışmanın sonuçlarını desteklemektedir. Araştırmanın diğer çalışmalardan farkını ortaya koymak amacıyla bu ilişkinin destinasyon aidiyeti tarafından aracılık edilip edilmediğine bakılmıştır. Elde edilen sonuçlar destinasyon deneyiminin destinasyon sadakati üzerinde belirlenen etkisinde destinasyon aidiyetinin kısmi aracı rolünün olduğunu göstermiştir. Bu sonuç ise daha önceden Yüksel vd., (2010), Cheng ve Huang(2011)'ın aidiyetin sadakat oluşum sürecinde öncül olabileceğini kanıtlar niteliktedir. Bu kapsamda aidiyetin kısmen de olsa tutumsal sadakat ile yakın bir ilişki içinde olduğu söylenebilir. Su vd., (2011) 'nin gerçekleştirmiş olduğu çalışmada da araştırmacılar genellikle destinasyon aidiyetini, bütünsel sadakati ve daha sonrasında da davranışsal sadakati etkileyen ve oluşturan tutumsal sadakatin ortaya çıkarılmasın da önemli bir husus olarak görmüşlerdir.

Fethiye'de uygulanan araştırmada elde edilen sonuçlar kapsamında ilgili destinasyona yönelik geliştirilen öneriler şu şekildedir;

- Deneyimin sadakat üzerinde etkisi aidiyet aracılığıyla gerçekleştirildiği düşünüldüğünde turistlerin farklı deneyimler ile destinasyona yönelik önce duygusal bir bağ olan aidiyet duygusunun oluşturulmasının yaşadıkları deneyimden memnun kalan turistlerin sadakat oluşturmasında daha etkili olacağı düşünülmektedir. Çünkü daha önce de bahsedildiği gibi aidiyet duygusu sadakat için öncül bir davranıştır ve bu duygusal süreç geliştirilmeden 
yani ön koşulu sağlanmadan oluşturulan sadakat uzun vadeli olmayacağı gibi bu amaç dahilinde yapılan yatırımlar ve harcamalarda amacına tam olarak hizmet veremeyecektir. Bu nedenle destinasyonlar kendilerini ziyaret eden turistlere kendilerini oraya ait hissettirecek turistlerin milliyetlerine, kültürlerine ve yaşam tarzlarına yönelik yapılar, ürünler ve hizmetler sunmalıdır. Kendilerini her zamanki yaşam alanlarına benzer veya yakın ortamlarda ve kültürlerde bulan turistler bu yolla ziyaret ettikleri destinasyona aidiyet geliştirerek tekrar ziyaret etme ve başkalarına tavsiye etme niyetleri oluşabilecektir.

- Duyuşşsal bir süreç olan aidiyetin sağlanması için tatilleri veya ziyaretleri süresince benzersiz bir deneyim yaşamayı amaçlayan turistlere destinasyona varışından ayrılışına kadar geçen sürede destinasyon yöneticileri, pazarlamacıları ve çalışanları tarafından yakından ilgi ve alaka gösterilmeli, turistlerin istek, intiyaç ve beklentilerinin mümkün olan en üst düzeyde karşılanması amaçlanmalıdır. Bu da destinasyon içerisinde yer alan işletmelerde istihdam edilen personelin turizm sektörüne olan yatkınlığı, güçlü insan ilişkilerine sahip olması gibi kişilik özellikleri ile birlikte işletmenin personel motivasyonu ile yakından ilgilidir. Turizm sektöründe çalışma ortamına uygun kişilik özelliklerine sahip ve çalışma ortamından ve yöneticilerinden memnun çalışan, gelen ziyaretçilerin unutulmaz deneyimler yaşamasına fırsat sunarken turist tatminini de artırabilmektedir. Bu yüzden insanın insan ile direk temasını gerektiren turizm sektöründe personel seçimi destinasyondaki turizm işletmeleri tarafından önem verilmesi gereken bir husus olarak karşımıza çıkmaktadır.

- Destinasyonun dünya düzeyinde önde gelen rakipleri ile yarışabilmesi için maliyetlerini en aza indirerek en fazla kar elde etmesi gerektiği bilinen bir husustur. Bu hususta turistlerde oluşturulacak destinasyon sadakati rekabet avantajı sağlamada kullanılabilecek yollardan birisidir. Destinasyon sadakatinin daha önce birçok kez söz edilen maliyeti düşürücü etkisi göz önüne alındığında da bu değişkene etki eden farklı değişkenlerin önemle dikkate alınması ve değerlendirilmesi gerektiği düşünülmektedir. Bu değişkenlerin içinde en önemlilerinden birisi de deneyim olarak karşımıza çıkmaktadır. Beklentilerinin üzerinde deneyim elde eden ziyaretçiler geliştirdikleri aidiyet duygusu ile sadık turist haline dönüşebilmektedir. Bu nedenle destinasyon pazarlamacıları, yöneticileri ve sektör uygulayıcıları destinasyonu ziyaret eden turistlere aidiyet duygularını geliştirmek ve sonrasında sadık müşteriler elde etmek için benzersiz ve turistlerin beklentilerinin üzerinde bir deneyim yaşatmaları önem arz ettiği düşünülmektedir. Bununla birlikte bilindiği üzere günümüzde diğer birçok sektörde olduğu gibi turizmde de kaynak, gelir vb. unsurların sürdürülebilirliği oldukça önemlidir. Farklılaştırma stratejisi ile ortaya koyulan deneyimlerin sadakata sağladığı faydaların sürdürülebilirliği ise geliştirilen hizmet ya da ürün üzerinde uzmanlaşma stratejisi ile mümkün olacağı düşünülmektedir. Ancak stratejilerin amacı kısa vadede elde edilecek kar için uzun vadedeki kazançlardan vazgeçilmemesidir. Bu kapsamda sürdürülebilirlik de geliştirilen ürün / hizmetin üzerinde uzmanlaşılması ve söz sahibi olunması ile yakından ilişkilidir. Üzerinde uzmanlaşılmış ve bu yolla marka haline dönüştürülmüş ürün ve hizmetler destinasyonun marka oluşum sürecinde itici güç ve dayanak haline gelebilir. 


\section{Kaynakça}

Altunışık, R., Coşkun, R., Bayraktaroğlu, S. ve Yıldırım, E. (2012). Sosyal Bilimlerde Araştırma Yöntemleri - SPSS Uygulamalı(Genişletilmiş 7. Baskı). Sakarya: Sakarya Yayıncılık.

Baron, R. M. ve Kenny, D. A. (1986), 'The Moderator - Mediator Variable Distinction in Social Psychological Research: Conceptual, Strategic, and Statistical Considerations', Journal of Personality and Social Psychology, 51(6), 11731182.

Bayram, N. (2013). Yapısal Eşitlik Modellemesine Giriş - Amos Uygulamaları (2. Baskı). Bursa: Ezgi Kitabevi.

Bianchi, C. ve Pike, S. (2011). "Antecedents of Destination Brand Loyalty For ALongHaul Market: Australia's Destination Loyalty Among Chilean Travelers", Journal of Travel \& Tourism Marketing, 28, 736-750.

Bosnjak, M., Sirgy, M. J., Hellriegel, S. ve Maurer, O. (2011). "Postvisit Destination Loyalty Judgments: Developing and Testing a Comprehensive Congruity Model", Journal of Travel Research, 50 (5), 496-508.

Brakus, J. J., Schmitt, B. H. ve Zarantonello, L. (2009), 'Brand Experience: What Is It? How Is It Measured? Does It Affect Loyalty?', Journal of Marketing, 73, 52-68.

Chen, J. S. ve Gürsoy, Doğan D. (2001), 'An Investigation of Tourists' Destination Loyalty and Preferences', International Journal of Contemporary Hospitality Management,13 (2), 79-85.

Chi, C. G-Q. (2011). "Destination Loyalty Formationand Travelers' Demographic Characteristics: A Multiple Group Analysis Approach", Journal of Hospitality \& Tourism Research, 35 (2), 191-212.

Chi, C. G-Q. (2012). "An Examination of Destination Loyalty: Differences Between First-Time and Repeat Visitors", Journal of Hospitality \& Tourism Research, 36 (1), 3-24.

Chi, C. G-Q. ve Qu, H. (2008). "Examining the Structural Relationships of Destination Image, Tourist Satisfaction and Destination Loyalty: An Integrated Approach", Tourism Management, 29, 624-636.

Çelik, S. ve Gökçe, F. (2015), 'Destinasyon Pazarlamasında Deneyimsel Pazarlama Uygulamalarının Kullanımına İlişkin Kavramsal Bir Çalışma' http://www.ejoir.org/klasik/belge/kasim2015/3.pdf. Erişim Tarihi: 28.03.2017.

Deng J. ve Pierskalla, C. (2011). "Impact of Past Experience on Perceived Value, Overall Satisfaction, and Destination Loyalty: A Comparison Between Visitor and Resident Attendees of a Festival", Event Management, 15, 163-177.

Dick, A. S. ve Basu, K. (1994). "Customer Loyalty: Toward an Integrated Conceptual Framework", Journal of the Academy of Marketing Science, 22 (2), 99-113.

Forgas-Coll, S., Palau-Saumell, R., Sanchez-Garcia, J. ve Callarisa-Fiol, L. J. (2012). "Urban Destination Loyalty Drivers and Cross-National Moderator Effects: The Case of Barcelona", Tourism Management, 33 (6), 1309-1320.

Hernandez, L., Solis, M. M., Moliner, M. A. ve Sanchez, J. (2006). "Tourism Destination Image, Satisfaction and Loyalty: A Study in Ixtapa-Zihuatanejo, Mexico", Tour Geographies, 8 (4), 343-358.

Kayış, A. (2009), 'SPSS Uygulamalı Çok Değişkenli İstatistik Teknikleri (4. Baskı)', Şeref Kalaycı (Ed.). Güvenilirlik Analizi (ss. 403-419). Ankara: Asil Yayın Dağıtım Ltd. Şti.

Kılıç, B. (2011). "Destinasyon Ziyaretçilerinin Sosyo-Demografik Özelliklerinin Sadakat Eğilimleri Üzerine Etkisi". Selçuk Üniversitesi Sosyal Bilimler Enstitüsü Dergisi, 26, 239-252. 
Kim, A. K. ve Brown, G. (2012). "Understanding the Relationships Between Perceived Travel Experiences, Overall Satisfaction and Destination Loyalty", Anatolia - An International Journal of Tourism and Hospitality Research, 23 (3), 328-347.

Kim, K. (2008), 'Analysis of Structural Equation Modelfor the Student Pleasure Travel Market: Motivation, Involvement, Satisfaction, and Destination Loyalty'. Journal of Travel \& Tourism Marketing, 24 (4), 297-313

Kozak, M., Bigne, E. ve Andreu, L. (2004). "Satisfaction and Destination Loyalty: A Comparison Between Non-Repeatand Repeat Tourists", Journal of Quality Assurance in Hospitality \& Tourism, 5 (1), 43-59.

Kyle, G., Graefe, A., Manning, R. ve Bacon, J. (2004), 'Predictors of Behavioral Loyalty among Hikers along the Appalachian Trail'. Leisure Sciences, 26 (1): 99-118.

Lee, J., Graefe, A. R. ve Burns, R. C. (2007). "Examining the Antecedents of Destination Loyalty in a Forest Setting", Leisure Sciences, 29, 463-481.

Lopez-Mosquera, N. ve Sanchez, M. (2013), 'Direct and Indirect Effects of Received Benefits and Place Attachment in Willingness to Pay and Loyalty in Suburban Natural Areas', Journal of Environmental Psychology, 34, 27-35.

McDowall, S. (2010). "International Tourist Satisfaction and Destination Loyalty: Bangkok, Thailand", Asia Pacific Journal of Tourism Research, 15 (1), 21-42.

Mechinda, P. Serirat, S. ve Gulid, N. (2009). "An Examination of Tourists' Attitudinal and Behavioral Loyalty: Comparison Between Domestic and International Tourists", Journal of Vacation Marketing, 15 (2), 129-148.

Mendes, J. C., Valle P. O., Guerreiro, M. M. ve Silva, J. A. (2010). "The Tourist Experience: Exploring the Relationship Between Tourist Satisfaction and Destination Loyalty", Tourism, 58 (2), 111-126.

Myagmarsuren, O. ve Chen, C-F. (2011). "Exploring Relationships Between Destination Brand Equity, Satisfaction, and Destination Loyalty: A Case Study of Mongolia", Journal of Tourism, Hospitality \& Culinary Arts, 3 (2), 81-94.

Oliver, R. L. (1999). "Whence Consumer Loyalty?", Journal of Marketing, 63, 33-44.

Oppermann, M. (2000). "Tourism Destination Loyalty", Journal of Travel Research, 39, 78-84.

Osman, H. Johns, N. ve Lugosi, P. (2014). "Commercial Hospitality in Destination Experiences: McDonald's and Tourists' Consumption of Space". Tourism Management, 42, 238-247

Otto, J. E. ve Ritchie, J. R. B. (1996). "The Service Experience in Tourism". Tourism Management, 17 (3), 165-174.

San Martin, H. Collado, J. ve Rodriguez del Bosque, I. (2013). "An Exploration of the Effects of Past Experience and Tourist Involvement on Destination Loyalty Formation", Current Issues in Tourism, 16 (4), 327-342.

Schermelleh-Engel, K, Moosbrugger, H. ve Müller, H. (2003). "Evaluating the Fit of Structural Equation Models: Tests of Significance and Descriptive Goodness-ofFit Measures", Methods of Psychological Research Online, 8 (2), 23-74.

Seçer, İ. (2015). Spss ve Lisrel ile Pratik Veri Analizi-Analiz ve Raporlaştırma (2. Baskı). Ankara: Anı Yayıncılık.

Sırakaya-Türk, E., Ekinci, Y. ve Martin, D. (2015), 'The Efficacy of Shopping Value in Predicting Destination Loyalty', Journal of Business Research, 68, 1878-1885.

Su, H.-J., Cheng, K-F. ve Huang, H-H. (2011), 'Empirical Study of Destination Loyalty and Its Antecedent: The Perspective of Place Attachment', The Service Industries Journal, 31, (16), 2721-2739.

Sun, X. Chi, C. G-Q. ve Xu H. (2013). "Developing Destination Loyalty: The Case of Hainan Island", Annals of Tourism Research, 43, 547-577.

Swarbrooke, J. ve Horner, S. (2007). Consumer Behaviour in Tourism (2. Baskı). Oxford: Butterworth-Heinemann. 
Taşkın Ç. ve Karadamar, A. A. (2016), 'Destinasyon Marka Bağlılığı: Yabancı Turistler Üzerine Diyarbakır Kentinde Bir Araştırma', Yönetim Bilimleri Dergisi / Journal of Administrative Sciences, 14 (28), 199-222

Tsai, S-P. (2012), 'Place Attachment and Tourism Marketing: Investigating International Tourists in Singapore', International Journal of Tourism Research, $14,139-152$.

Ural, A. ve Kılıç, İ. (2006), Bilimsel Araştırma Süreci ve SPSS ile Veri Analizi(2. Baskı), Ankara: Detay Yayıncılık.

Valle, P.O., Silva, J. A., Mendes, J., ve Guerreiro, M. (2006). "Tourist Satisfaction and Destination Loyalty Intention: A Structural and Categorical Analysis", International Journal of Business Science and Applied Management, 1 (1), 2544.

Veasna, S., Wu, W.-Y. ve Huang, C.-H. (2013), 'The Impact of Destination Source Credibility on Destination Satisfaction: The Mediating Effects of Destination Attachment and Destination Image', Tourism Management, 36, 511-526.

Weber, K. (2001). "Association Meeting Planners' Loyalty to Hotel Chains", Hospitality Management, 20, 259-275.

Wu, C.-W. (2016). "Destination Loyalty Modeling of the Global Tourism", Journal of Business Research, 69, 2213-2219.

Yoo, M. ve Bai, B. (2013), 'Customer Loyalty Marketing Research: A Comparative Approach Between Hospitality and Business Journals'. International Journal of Hospitality Management, 33, 166-177.

Yoon, Y. ve Uysal, M. (2005). "An Examination of the Effects of Motivation and Satisfaction on Destination Loyalty: A Structural Model", Tourism Management, 26, 45-56.

Yüksel A., Yüksel F. ve Bilim, Y. (2010), 'Destination Attachment: Effects on Customer Satisfaction and Cognitive, Affective and Conative Loyalty', Tourism Management, 31, 274-284. 